\title{
ЕВРОПЕЙСКИЕ ВЫБОРЫ 2019: \\ ПРОГРАММНЫЕ ПОДХОДЫ И ЭЛЕКТОРАЛЬНЫЕ ПЕРСПЕКТИВЫ ВЕДУЩИХ ОБЩЕЕВРОПЕЙСКИХ ПАРТИЙ
}

\begin{abstract}
Аннотация. В мае этого года в Евросоюзе пройдут очередные выборы депутатов Европарламента. Ведущие общеевропейские партии ведут активную избирательную кампанию, опубликовали свои предвыборные документы, определили своих кандидатов на пост Главы Еврокомиссии (шпиценкандидат) и т.д. На результаты этих выборов серьёзное влияние окажут финансово-экономический и миграчионный кризисы, брекзит, поляризачия между различными регионами Евросоюза, рост популярности евроскептических и популистских партий. Автор анализирует влияние этих факторов и делает прогноз результатов указанных выборов для ведущих общеевропейских партий, в том числе в региональном разрезе.

Ключевые слова: Евросоюз, европейские выборы, Европарламент, предвыборные программы, шпиценкандидат, евроскептические партии.

В конце мая 2019 г. во всех странах - членах Европейского союза пройдут выборы депутатов Европейского парламента (ДЕП). Они вызывают интерес по ряду причин. Во-первых, в соответствии с Лиссабонским договором права Европарламента (ЕП) расширяются ${ }^{1}$. Во-вторых, эти выборы являются уникальной возможностью для общеевропейских политических партий представить свои программные документы и лидеров, которые намерены номинироваться на пост Председателя Европейской комиссии, избираемого новым составом Европарламента. В-третьих, в большинстве стран ЕС усилилась популярность евроскептических партий, представленных в нынешнем составе ЕП. Скорее всего в новом ЕП их представительство будет больше 2 . В-четвёртых, в ЕС всё отчётливее наблюдается поляризация между различными регионами. С одной стороны, бывшие члены социалистического лагеря: Болгария, Венгрия, Польша, Чехия все более активно противостоят старым членам ЕС: ФРГ, Франции и др. С другой стороны, среди старожилов ЕС наметились серьёзные разночтения, а именно: демарш Англии, особая позиция нового руководства Италии и Греции, в т.ч. в отношении с РФ, и пр.
\end{abstract}

\section{Итоги предыдущих выборов 2014 г.}

В настоящий момент в ЕП функционируют восемь фракций, аффилированных с определёнными общеевропейскими партиям. В табл. 1 представлены итоги выборов депутатов Европейского парламента 2014 г.

(C) Гуселетов Борис Павлович - доктор политических наук, ведущий научный сотрудник Центра партийно-политических исследований Отдела социальных и политических исследований ИЕ РАН. $\boldsymbol{A} \boldsymbol{\delta}$ pec: 125009, Россия, Москва, ул. Моховая, д. 11, стр. 3.E-mail: bgusletov@mail.ru.

DOI: http://dx.doi.org/10.15211/vestnikieran220194451

${ }^{1}$ Кавешников Н.Ю. Лиссабонский договор: как меняется Европейский союз. Сайт «Перспектива» сетевого издания Центра исследования и аналитики Фонда историческая перспектива. URL: http://www.perspektivy.info/oyk umena/europe/lissanbonskij_dogovor_kak_menajetsa_jevropejskij_sojuz_2009-12-22.htm (дата обрашения: 02.02.2019).

${ }^{2}$ Гуселетов Б. Евроскептики в канун очередных выборов в Европейский парламент. Доклады Института Европы РАН, № 357, М., ИЕ РAН, 2018 г. С. 29-36. URL: http://www.instituteofeurope.ru/images/uploads/doklad/357.pdf (дата обращения: 02.02.2019). 
Итоги выборов депутатов Европарламента 2014 г. ${ }^{1}$

Таблица 1

\begin{tabular}{|c|c|c|c|c|}
\hline № & Фракция & Партия & $\begin{array}{l}\text { Количество ДЕП, }(\% \\
\text { от общего числа) }\end{array}$ & \begin{tabular}{|l} 
Ведущие страны ЕС по \\
числу ДЕП во фракции \\
\end{tabular} \\
\hline 1 & $\begin{array}{l}\text { Европейская народная } \\
\text { партия }\end{array}$ & $\begin{array}{l}\text { Европейская народная партия } \\
(\text { ЕНП) - Проевропейская, (ПрЕ) }\end{array}$ & $217(28,89 \%)$ & $\begin{array}{l}\text { ФРГ, } 34 \\
\text { Польша, } 22 \\
\text { Франция, } 20\end{array}$ \\
\hline 2 & $\begin{array}{l}\text { Альянс социалистов и } \\
\text { демократов ПАСД }\end{array}$ & $\begin{array}{l}\text { Партия европейских социалистов } \\
(\text { ПЕС) - ПрЕ }\end{array}$ & $190(25,29 \%)$ & $\begin{array}{l}\text { Италия, } 31 \\
\text { ФРГ, } 27 \\
\text { Англия, } 20\end{array}$ \\
\hline 3 & $\begin{array}{l}\text { Европейские консерва- } \\
\text { торы и реформисты }\end{array}$ & $\begin{array}{l}\text { Европейские консерваторы и ре- } \\
\text { формисты (ЕКР) - Мягкие евро- } \\
\text { скептики (МЕС) }\end{array}$ & $74(9,85 \%)$ & $\begin{array}{l}\text { Англия, } 19 \\
\text { Польша, } 16 \\
\text { ФРГ, } 6\end{array}$ \\
\hline 4 & $\begin{array}{l}\text { Альянс либералов и } \\
\text { демократов за Европу }\end{array}$ & $\begin{array}{l}\text { Альянс либералов и демократов за } \\
\text { Европу (АЛДЕ) - ПрЕ }\end{array}$ & $70(9,32 \%)$ & $\begin{array}{l}\text { Бельгия, } 12 \\
\text { Испания, } 8 \\
\text { Голландия, } 7\end{array}$ \\
\hline 5 & $\begin{array}{l}\text { Европейские левые- } \\
\text { Зелёные Севера (ЕЛ) }\end{array}$ & $\begin{array}{l}\text { Партия европейских левых (ПЕЛ) } \\
\text { - МЕС }\end{array}$ & $52(6,92 \%)$ & $\begin{array}{l}\text { Испания, } 11 \\
\text { ФРГ, } 8 \\
\text { Греция, } 6\end{array}$ \\
\hline 6 & $\begin{array}{l}\text { Зелёные - Европейский } \\
\text { свободный альянс (ЗСА) }\end{array}$ & $\begin{array}{l}\text { Европейская партия зелёных (ЕПЗ) } \\
-П р Е\end{array}$ & $50(6,66 \%)$ & \begin{tabular}{|l|} 
ФРГ, 13 \\
Англия и \\
Франция по 6
\end{tabular} \\
\hline 7 & $\begin{array}{l}\text { Европа свободы и пря- } \\
\text { мой демократии (ЕСПД) }\end{array}$ & $\begin{array}{l}\text { Альянс за прямую демократию в } \\
\text { Европе (АПД) - МЕС }\end{array}$ & $45(5,99 \%)$ & \begin{tabular}{|l|} 
Англия, 16 \\
Италия, 14 \\
Франция, 6
\end{tabular} \\
\hline 8 & $\begin{array}{l}\text { Европа наций и свобод } \\
\text { (ЕНС) }\end{array}$ & $\begin{array}{l}\text { Европа наций и свобод (EHC) - } \\
\text { Жёсткие евроскептики }\end{array}$ & $39(5,19 \%)$ & $\begin{array}{l}\text { Франция, } 15 \text { Италия, } 6 \\
\text { Голландия, } 4\end{array}$ \\
\hline 9 & Независимые & & $14(1,86 \%)$ & \\
\hline
\end{tabular}

В нынешнем ЕП лидирующие позиции занимают проевропейские партии ЕНП, ПЕС и АЛДЕ, имеющие 479 из 751 депутатских места, что позволяет им полностью контролировать состав Еврокомиссии (из 28 еврокомиссаров у ЕНП 14, ПАСД - 8 и АЛДЕ - 5, 1 независимый еврокомиссар от Великобритании) и руководство основными постоянными комитетами Европарламента (из 25 комитетов у ЕНП и ПАСД по 8 руководителей, у АЛДЕ - 5, ЕКР - 2, ЕЛ, ЗСА по 1). Председателями Еврокомиссии и Европейского парламента являются представители ЕНП Ж.-К. Юнкер и А. Таяни, соответственно.

\section{Предвыборные программы основных общеевропейских партий}

Эти партии накануне и в ходе избирательной кампании обнародовали свои предвыборные манифесты или иные документы.

Так, например, ведущая общеевропейская Народная партия (ЕНП), имеющая самую большую фракцию в Европарламенте действующего созыва на своём сайте достаточно давно обнародовал так называемые обязательства (commitments), касающиеся будущего Евросоюза и Европы в целом, правосудия и безопасности, рабочих мест и роста экономики, предпринимательства и инноваций, международных отношений, трансатлантическое торговое и инвестиционное партнерство, цифровое общество, окружающая среда, энергетика, изменение климата, сельское хозяйство, Западные Балканы, южное соседство, восточное партнёрство, навыки и мобильность, евро и инвестиции, инклюзивное общество ${ }^{2}$. Все эти разделы содержат правильные, но весьма общие слова о дальнейшем расширении и укреплении ЕС, развитии и

\footnotetext{
${ }^{1}$ Гуселетов Б.П. Подготовка к выборам в европейский парламент и их результаты. Выборы в Европейский парламент 2014: итоги и перспективы. Сб. статей. Ред. кол.: В.Я. Швейцер, Б.П. Гуселетов, Н.С. Плевако. М., ИЕ PAН, 2014. 244 с. (Библиотека Института Справедливый Мир, Институт Европы РАН, Институт Справедливый Мир; Вып. 34). С. 25-37.

${ }^{2}$ Сайт Европейской народной партии. URL: https://www.epp.eu/our-commitments/commitments/ (дата обращения: 10.04.2019).
} 
продвижении демократических ценностей, борьбе с терроризмом и наркотрафиком, необходимости создания новых рабочих мест и повышении мобильности рабочей силы в рамках ЕС, поддержке предпринимательства и инноваций, укрепления роли Евросоюза в мире, включая отношения с США, соседними странами и т.д. Но совершенно очевидно, что всё это имеет слабое отношение к современным реалиям Европы. Как показывают многочисленные опросы общественного мнения в странах ЕС сегодня подавляющее большинство граждан этих стран волную такие проблемы как иммиграция, терроризм, экономическая ситуация, безработица, финансирование общественных услуг ${ }^{1}$. А найти актуальные ответы именно на эти вопросы в представленных ЕНП документов оказалось крайне затруднительно.

В Манифесте ПЕС, опубликованном на сайте партии ${ }^{2}$, традиционно для социал-демократов основной акцент делается на проблемах равенства, справедливости и солидарности ${ }^{3}$. ПЕС традиционно поддерживает участие в профсоюзах и эффективный диалог между наёмными работниками и работодателями. Второй раздел называется «Европа солидарности для многих, а не для нескольких», в котором, например, говориться, что «Социальныле права граждан дол-жны иметь приоритет над экономическими свободами крупных корпораций... Европе нужен более сильный бюджет для обеспечения сплоченности и солидарности между гражданами, регионами и странами».

Большое внимание в Манифесте уделяется вопросам экологии, свободы и демократии, гендерному равенству, поддержке молодёжи, а также усилению роли Европы в мире. В общем и целом этот документ является традиционным для европейской социал-демократии, основными своим и оппонентами они называют националистов и консерваторов. При этом о таких проблемах как отношения рост терроризма, с США, Китаем, Россией, миграция, снижение уровня благосостояния большинства граждан в странах ЕС и другие, сильно волнующей европейских избирателей (см. выше) в нём почти ничего не говорится, что несомненно является его большим минусом с учетом значительной актуальности этой проблемы.

Наиболее содержательным выглядит предвыборный манифест ещё одной проевропейской партии Альянс либералов и демократов Европы (АЛДЕ), названный «Свобода, возможности, процветание: либеральное видение будущего Европы» ${ }^{4}$. В этом 12 -страничном документе даны вполне конкретные ответы на все основные актуальные проблемы, волнующие граждан ЕС. Естественно, что АЛДЕ отдаёт дань уважения основополагающим либеральным ценностям и даже заявляет, что «европейские ценности - это либеральные ценности», что выглядит достаточно спорным с точки зрения тех же социал-демократов.

Европейские либералы уверены, что «... наше разнообразие - это наша сила... прогресс для всех и поддержка уязвимых слоёв населения могут быть достигнуты за счёт динамики рыночной экономики с помощью конкуренции, справедливости и открытой торговли». Своими основными оппонентами либералы видят «Авторитарные, националистические и популистские движения внутри ЕС стремятся подорвать открытость, плюрализм и терпимость в основе европейского проекта. Эти антилиберальные силы стремятся к культурному конфликту». Либералы хотят, «чтобы Европа была сильной, желающей и способной действовать и быть в авангарде глобальных событий» и намерены «вести ЕС вперед и адаптироваться к меняющимся реалиям XXI века».

\footnotetext{
${ }^{1}$ Сайт POLITICO. European elections 2019: Most important issues facing the EU. URL: https://www.politico.eu/ interactive/european-elections-most-important-issues-facing-the-eu/ (дата обращения: 10.04.2019).

${ }_{3}^{2}$ Сайт Партии европейских социалистов. URL: https://www.pes.eu/manifesto2019 (дата обращения: 10.04.2019).

${ }^{3}$ Там же.

${ }^{4}$ Сайт Альянса либералов и демократов. URL: https://www.aldeparty.eu/sites/alde/files/40-Resolutions/2019_freedom_opportunity_prosperity_the_liberal_vision_for_the_future_of_europe.pdf (дата обращения: 10.04.2019).
}

Научно-аналитический вестник ИЕ РАН, 2019, №2 
Для решения проблемы наплыва мигрантов в Европу либералы предлагают следующее: «В своём нынешнем состоянии система убежища и миграции в ЕС больше не подходит для этой цели. Нам нужен новый общий европейский ответ, основанный на долгосрочном видении. Либералы решительно выступают против всех форм расизма, разделения общества и ненависти к людям. Либералы будут стремиться обеспечить защиту всех тех, кто бежит от ужасов войны или боли политических репрессий. Мы подчёркиваем нашу приверженность Женевской конвенции о статусе беженцев и право на убежище... ЕС должен стремиться предоставить убежище в регионе, откуда приехали искатели убежища. Для этого ЕС должен заключить миграционные соглашения с безопасными странами на Ближнем Востоке и в Африке».

Большое внимание в документе уделено проблеме экологии и изменения климата. Либералы считают, что «расширение международного сотрудничества в области климата и окружающей среды имеет решающее значение для достижения целей Парижского соглашения и Целей в области устойчивого развития (ЦРТ), и что ЕС должен занять глобальное лидерство в определении глобальных амбициозных целей. Для достижения этих целей мы должны завершить создание Энергетического союза и двигаться в направлении стимулирования исследований и разработок в области технологий с низким уровнем выбросов, инфраструктуры, производства экологически чистой энергии, энергоэффективности и сокращения выбросов в промышленности и на транспорте, включая авиацию и судоходство».

В сфере международных отношений либералы, поддерживая важную роль НАТО в обеспечении безопасности на европейском континенте, тем не менее, предлагают добиваться более тесного сотрудничества в борьбе с терроризмом, а также более эффективных усилий по защите внешней границы ЕС.

Таким образом, можно констатировать, что предвыборный манифест АЛДЕ является весьма актуальным и конкретным документом, в котором сделана попытка дать ответы на все основные вопросы, волнующие европейских избирателей.

Определённый интерес представляет предвыборный манифест ещё одной проевропейской партии Европейских Зелёных ${ }^{1}$. В нём европейские зелёные определили своих основных политических оппонентов и выдвинули «12 зелёных приоритетов для изменения Европы». Что касается оппонентов, Зелёные заявили, что они «будут работать над тем, чтобы отбросить и изолировать тех, кто пытается превратить действительную критику недостатков и ошибок в антиевропейский, экстремистский и ксенофобский откат. Мы говорим нет Европе национализма».

Что касается основных приоритетов, то среди них, естественно, главенствующее положение занимают вопросы охраны окружающей среды: «Борьба с изменением климата путём поэтапного отказа от угля, повышения энергоэффективности и 100\% переход на возобновляемые источники энергии; Инвестиции в справедливую зелёную экономику, исследования и инновации; Сделать поезда реальной альтернативой самолетам в Европе; Защита здоровья граждан, путём борьбы с загрязнением воздуха и воды и сокращения пластиковых отходов; Производство качественной местной пищи, не содержащей ГМО и пестицидов, организация сельского хозяйства без жестокого обращения с животными».

Большое внимание зелёные уделили социальным вопросам: «Гарантии достойного минимального дохода; Обеспечение бесплатного доступа к качественному образованию, справедливо оплачиваемых стажировок и хорошей работы для молодёжи; Поддержка верховенства закона и основных прав, повышение прозрачности и борьба с коррупцией; Борьба за фе-

\footnotetext{
1 Сайт партии Европейских Зелёных. URL: https://europeangreens.eu/priorities-2019-what-european-greens-fight (дата обращения: 02.02.2019).
}

Научно-аналитический вестник ИЕ РАН, 2019, №2 
министскую Европу, против насилия по признаку пола и за равные права для всех».

В сфере экономики зелёные предлагают: «Добиваться налоговой справедливости за счёт разработки налоговых режимов, которые не будут давать привилегии крупным многонациональным корпорациям и состоятельным лицам: борьбы с налоговыми убежищами, уклонением от уплаты налогов и отмыванием денег».

Проблему наплыва мигрантов зелёные предлагают решить путём предоставления: «Права на убежище и создания законных и безопасных каналов для миграции; политика убежища должна основывалась на солидарности, гуманности и упорядоченном процессе, включая справедливое распределение обязанностей между государствами-членами и восстановление европейской миссии по спасению моря..., а также создания общих стандартов и правила мобильности рабочей силы и миграции... ЕС должен оказывать поддержку странам и муниципалитетам в интеграции беженцев или мигрантов».

И, наконец, последний приоритет предусматривает «Прекращение экспорта оружия диктаторам и воюющим сторонам и содействие развитию мирового сообщества. Европа должна увеличить финансирование сотрудничества в целях развития, чтобы оно достигло не менее $0,7 \%$ ВВП... для предотвращения, разрешения и смягчения гражданских конфликтов».

Таким образом, можно констатировать, что Зелёные в своём предвыборном манифесте объединили идеологические установки экологического и социал-демократического направлений. При этом они попытались дать вполне конкретные ответы на ряд наиболее актуальных вопросов, волнующих европейских избирателей.

Рассмотрим ещё один предвыборный Манифест ${ }^{1}$ общеевропейской партии Европейский свободный альянс (ЕСА), которая представляет и отстаивает интересы национальных меньшинств. В Европарламенте ЕСА образует общую фракцию с партией Европейских зелёных.

В своём предвыборном Манифесте ЕСА в качестве своих основных оппонентов называет «Евроскептицизм и/или антиевропейский популизм, которые не предлагают решений» и естественно делает основной акцент на защите прав и интересов национальных меньшинств и малых народов Европы. В данном документе говорится, что «ЕСА защищает более широкое и всеобъемлющее видение Европы, основанное на желании признать и развивать её разнообразие. Для ЕСА крайне важно, чтобы Европа принимала и включала все народы в процесс принятия решений, чтобы построить демократическую Европу мира, уважения и солидарности. ЕСА хотел бы решительно построить социальную Европу». ЕСА предлагает создать на европейском уровне «Ассамблею регионов и народов», которая должна заменить «беззубый Комитет регионов». При этом ЕСА отстаивает и принципы демократии, свободы и социальной справедливости. В Манифесте по этому поводу говорится: «Культурное и языковое разнообразие, социальная справедливость и право на самоопределение взаимосвязаны. Новый проект для Европы народов необходим для решения демократических задач и расширения прав и возможностей, к которым стремятся народы Европы. ЕСА стремится к современной, амбициозной и процветающей Европе, причём не только в экономическом, но и в социальном и демократическом плане».

ЕСА отдаёт дань экологической проблематике: «Европейский Свободный Альянс поддерживал и защищал большую защиту окружающей среды и биоразнообразия с момента его основания. Он стремится ограничить воздействие человеческой деятельности на окружающую среду и защитить европейских граждан от всех экологических рисков для их здоровья; такие как запрещение генетически модифицированных организмов и глифосата».

\footnotetext{
${ }^{1}$ Сайт партии Европейский свободный альянс. URL: https://dev.e-f-a.org/2019-manifesto-european-free-alliance/ (дата обращения: 02.02.2019).
}

Научно-аналитический вестник ИЕ РАН, 2019, №2 
ECA также защищает гендерное равенство: «Женщины по-прежнему недопредставлены на руководящих должностях в Европе. EFA считает, что участие женщин в общественной и политической жизни гарантирует более справедливые, более демократичные и более разнообразные общества». Особый акцент ЕСА делает на поддержку молодёжи: «ЕСА через свою молодёжную ветвь твердо привержен обеспечению полных возможностей для молодёжи и расширению их участия в жизни общества».

Таким образом, предвыборный Манифест ЕСА в значительной мере совпадает с аналогичным документом их главного партнёра Европейских зелёных. Единственное отличие, которое не носит принципиального характера - это поддержка национальных меньшинств и малых народов. В остальном же Манифест ЕСА - это смесь социал-демократических, экологических и либеральных идей.

\section{Прогноз результатов выборов депутатов Европарламента 2019}

Компания POLITICO опубликовала прогноз выборов депутатов Европарламента 2019², согласно которому композиция нового ЕП (705 ДЕП) может выглядеть так (см. табл. 2).

Таблица 2

Возможная композиция нового состава ЕП

\begin{tabular}{|c|c|c|c|}
\hline № & Фракция & $\begin{array}{c}\text { Количество ДЕП, (\% от } \\
\text { общего числа) }\end{array}$ & Ведущие страны ЕС по числу депутатов в группе \\
\hline 1 & ЕНП & $177(25,95 \%)$ & ФРГ 28, Польша 17, Испания, Франция по 13 \\
\hline 2 & ПАСД & $137(19 \%)$ & Италия, Испания по 18, ФРГ 16, Португалия и Румыния по 10 \\
\hline 3 & АЛДЕ & $66(9,36 \%)$ & Испания 10, ФРГ 9, Чехия 8, Голландия 7 \\
\hline 4 & EKP & $62(7,51 \%)$ & Польша, 27 Голландия 6, Швеция 5, Бельгия, Франция, Италия по 4 \\
\hline 5 & $\mathrm{EHC}$ & $59(8,22 \%)$ & Италия 28, Франция 21, Австрия 5 \\
\hline 6 & ПЕЛ-ЗС & $49(7,37 \%)$ & ФРГ, Испания по 8, Франция и Греция по 7 \\
\hline 7 & 3-ECA & $46(6,24 \%)$ & ФРГ19, Франция 7, Чехия 4 \\
\hline 8 & Новые партии & $41(6,38 \%)$ & Румыния 10, Испания 8, Германия и Польша по 5 \\
\hline 9 & Движение 5 Звезд & 23 & Италия 18, Польша 3, Хорватия 2 \\
\hline 10 & Республика на марше & $22(3,12 \%)$ & Франция \\
\hline 11 & ЕСПД & $15(5,81 \%)$ & ФРГ 18, Литва и Словакия по 1 \\
\hline 12 & Независимые & $8(1 \%)$ & \\
\hline
\end{tabular}

Как видно из табл. 2 ведущие проевропейские партии ЕНП, ПЕ и АЛДЕ, хотя и сохранят относительное большинство в новом составе Европарламента (380 из 705), но значительно сократят своё представительство даже с учётом того, что к ним может присоединиться ДЕП от партии Президента Франции Э. Макрона «Республика на марше». И это позволит им выбрать своих Председателя и членов Еврокомиссии и Спикера Европарламента.

Заметно усилит свои позиции жёсткая евроскептическая партия «Европа наций и свобод» в основном за счёт представителей партии Лига из Италии. В целом все евроскептические партии (ЕНС, ЕКР, ПЕЛ, АПД) будут контролировать примерно 30\% депутатских мест в Европарламенте, что позволит им претендовать на занятие ведущих позиций в этом органе: руководителей ряда комитетов и комиссий.

Усилят свои позиции и представители новых стран - членов ЕС Польши, Венгрии, Чехии и др., а они, как известно, настроены весьма скептически к нынешнему состоянию дел внутри ЕС и несомненно будут настаивать на его существенной трансформации в интересах этих стран.

\section{Список литературы}

Кавешников Н.Ю. Лиссабонский договор: как меняется Европейский союз. Сайт «Пер-

${ }^{1}$ Сайт POLITICO. URL: https://www.politico.eu/2019-european-elections/ (дата обращения: 02.02.2019). Научно-аналитический вестник ИЕ РАН, 2019, №2 
спектива» сетевого издания Центра исследования и аналитики Фонда историческая перспектива. URL: http://www.perspektivy.info/oykumena/europe/lissanbonskij_dogovor_kak_menajetsa_ jevropejskij_sojuz_2009-12-22.htm (дата обращения: 12.04.2019).

Гуселетов Б. Евроскептики в канун очередных выборов в Европейский парламент. Доклады Института Европы РАН, № 357, М., ИЕ РAH, 2018 г. С. 29-36. URL: http://www.instituteofeurope.ru/images/uploads/doklad/ 357.pdf (дата обращения: 12.04.2019).

Гуселетов Б.П. Подготовка к выборам в европейский парламент и их результаты. Выборы в Европейский парламент 2014: итоги и перспективы. Сб. статей. Ред. кол.: В.Я. Швейцер, Б.П. Гуселетов, Н.С. Плевако. М., ИЕ РАН, 2014. 244 с. (Библиотека Института Справедливый Мир, Институт Европы РАН, Институт Справедливый Мир; Вып. 34). С. 25-37.

Сайт Европейской народной партии. URL:https://www.epp.eu/ourcommitments/commitments/ (дата обращения: 12.04.2019).

Сайт POLITICO. European elections 2019: Most important issues facing the EU. URL: https://www.politico.eu/interactive/european-elections-most-important-issues-facing-the-eu/ (дата обращения: 12.04.2019).

Сайт Партии европейских социалистов. URL: https://www.pes.eu/manifesto2019 (дата обращения: 12.04.2019).

Сайт Альянса либералов и демократов. URL: https://www.aldeparty.eu/sites/alde/files/40-Re solutions/2019_freedom_opportunity_prosperity_the_liberal_vision_for_the_future_of_europe.pdf (дата обращения: 12.04.2019).

Сайт партии Европейских Зелёных. URL: https://europeangreens.eu/priorities-2019-whateuropean-greens-fight (дата обращения: 12.04.2019).

Сайт партии Европейский свободный альянс. URL: https://dev.e-f-a.org/2019-manifestoeuropean-free-alliance/ (дата обращения: 12.04.2019).

Сайт POLITICO. URL: https://www.politico.eu/2019-european-elections/ (дата обращения: 12.04.2019).

\section{References}

Kaveshnikov N.Y. Treaty of Lisbon: how the European Union is changing. The website «Perspective» of the online publication of the Center for Research and Analytics of the Foundation is a historical perspective. URL: http://www.perspektivy.info/oykumena/europe/lissanbonskij_dogovor _kak_menajetsa_jevropejskij_sojuz_2009-12-22.htm (date of the application: 12.04.2019).

B. Guseletov. Euro skeptics on the eve of the next elections to the European Parliament. Reports of the Institute of Europe, Russian Academy of Sciences, № 357, M., 2018. P. 29-36. URL: http:// www.instituteofeurope.ru/images/uploads/doklad/ 357.pdf (date of the application: 12.04.2019).

Guseletov B.P. Preparations for the elections to the European Parliament and their results. European Parliament Elections 2014: Results and Prospects. Sat articles. Ed. col.: V.Ya. Schweizer, B.P. Guseletov, N.S. Plevako. M., IE RAS, 2014. 244 s. (Library of the Institute Just Peace, Institute of Europe, RAS, Institute Just Peace; Issue 34). P. 25-37.

Web site of European People Party. URL:https://www.epp.eu/our-commitments/commitments/ (date of the application: 12.04.2019).

Web site POLITICO. European elections 2019: Most important issues facing the EU. URL: https://www.politico.eu/interactive/european-elections-most-important-issues-facing-the-eu/ (date of the application: 12.04.2019).

Web site o Party of European Socialists. URL: https://www.pes.eu/manifesto2019 (date of the application: 12.04.2019).

Научно-аналитический вестник ИЕ РАН, 2019, №2 
Web site of Alliance of Liberals and Democrats. URL: https://www.aldeparty.eu/sites/alde/ files/40-Resolutions/2019_freedom_opportunity_prosperity_the_liberal_vision_for_the_future_of_ europe.pdf (date of the application: 12.04.2019).

Web site of Party of European Greens. URL: https://europeangreens.eu/priorities-2019-whateuropean-greens-fight (дата обращения: 02.02.2019).

Web site of Party European Freee Alliance. URL: https://dev.e-f-a.org/2019-manifestoeuropean-free-alliance/ (date of the application: 12.04.2019).

Web site POLITICO. URL: https://www.politico.eu/2019-european-elections/ (date of the application: 12.04.2019).

\section{Programme Approaches and Electoral Prospects of the Leading European Parties in the Elections of 2019}

Author. Boris Guseletov, Doctor of Sciences (Polit.), Senior Research Fellow, Institute of Europe, Russian Academy of Sciences. Address: 11-3, Mokhovaya str., Moscow, Russia, 125009. E-mail: bgusletov@mail.ru.

Abstract. In May of this year, the next elections of deputies of the European Parliament will be held in the European Union. The leading all-European parties are conducting an active election campaign, have published their election documents, identified their candidates for the post of Head of the European Commission (candidate candidate for nomination), etc. The results of these elections will be seriously affected by financial, economic and migration crises, Brexit, polarization between different regions of the European Union, the growing popularity of Euroskeptical and populist parties. The author analyzes the influence of these factors and makes a forecast of the results of these elections for the leading pan-European parties, including in the regional context.

Key words: European Union, European elections, European Parliament, electoral programs, leading candidate, Eurosceptic parties.

DOI: http://dx.doi.org/10.15211/vestnikieran220194451 